\title{
Expressão Citofotométrica do Marcador CD-34 no Adenocarcinoma de Cólon
}

\section{CD-34 Cytophotometric Expression in Colon Adenocarcinoma}

\author{
JOÃO BATISTA MONTEIROTAJRA ${ }^{1}$; OSVALDO MALAFAIA ${ }^{2}$; JURANDIR MARCONDES RIBAS-FILHO 3 ; \\ NICOLAU GREGORI CZECZKO ${ }^{4}$; PAULOAFONSO NUNES NASSIF ${ }^{5}$; MARILEIDE INÁCIO DASILVA ${ }^{6}$
}

\begin{abstract}
${ }^{1}$ Mestre pelo Programa de Pós-Graduação em Princípios da Cirurgia do Hospital Universitário Evangélico de Curitiba I Faculdade Evangélica do Paraná; ${ }^{2}$ Livre Docente e Doutor em Cirurgia, Coordenador do Programa de PósGraduação em Princípios da Cirurgia do Hospital Universitário Evangélico de Curitiba / Faculdade Evangélica do Paraná; ${ }^{3}$ Mestre e Doutor em Cirurgia, Professor Adjunto da Faculdade Evangélica do Paraná ${ }^{4}$ Mestre e Doutor em Cirurgia, Professor Adjunto da Faculdade Evangélica do Paraná; ${ }^{5}$ Mestre e Doutor em Cirurgia, Professor Adjunto da Faculdade Evangélica do Paraná; ${ }^{6}$ Aluna do Programa de Pós-Graduação em Princípios da Cirurgia do Hospital Universitário Evangélico de Curitiba / Faculdade Evangélica do Paraná.
\end{abstract}

TAJRA JBM; MALAFAIA O; RIBAS-FILHO JM; CZECZKO NG; NASSIF PAN; SILVA MI. Expressão Citofotométrica do Marcador CD-34 no Adenocarcinoma de Cólon. Rev bras Coloproct, 2008;28(4): 409-413.

RESUMO: A angiogênese é uma das responsáveis pelo equilíbrio homeostático entre as células. Durante o desenvolvimento do processo de degeneração maligna celular o seu desequilíbrio é considerado um importante marco neoplásico e o CD-34 parece ser um bom marcador de angiogênese. Objetivos - Avaliar qual a expressão citofotométrica do CD-34 no adenocarcinoma de cólon; se apresenta alterações nas diferentes fases evolutivas na classificação modificada de Dukes; e como se expressa no cólon direito e esquerdo. Métodos - Utilizaram-se 19 casos submetidos à técnica imunoistoquímica com anticorpo anti CD-34. Após, as lâminas foram lidas pelo sistema SAMBA com o software Immuno 4, analisando dois índices: marcação e densidade óptica. Os parâmetros foram marcação e expressão do marcador, quer individual quer relacionado à classificação de Dukes e lado. Resultados - A média do índice de marcação foi 66,54 e densidade óptica 43,60. Em relação à classificação de Dukes, 12 do tipo B, tiveram índice de marcação 67,95 e densidade óptica 43,21 e, para os sete do tipo C, índice de marcação 64,12 e densidade óptica 44,27. Não foi possível identificar diferença em relação à classificação de Dukes. Quanto ao lado do tumor, os 11 esquerdos tiveram índice de marcação 72,08 e densidade óptica 46,70, e os oito direitos, índice de marcação 58,93 e densidade óptica 39,44. Em relação ao índice de marcação houve diferença significante, mas quanto à densidade óptica não. Conclusões - O CD-34 apresentou expressão discreta como marcador de angiogênese; sem diferença entre tipos B e C de Dukes mostrando atividade angiogênica maior à direita do que à esquerda.

Descritores: Neoplasias do cólon. CD-34. Imunoistoquímica. Classificação de Dukes. Angiogênese.

\section{INTRODUÇÃO}

O adenocarcinoma de cólon é a segunda causa mais comum de morte por câncer em homens e mulheres, sendo responsável por mais de cinco milhões de óbitos por ano. Na época de aparecimento apenas $70 \%$ dos tumores são ressecáveis, sendo $75 \%$ curáveis, entretanto $25 \%$ terão recorrência da doença ${ }^{1}$.

Os pólipos colorretais podem dar origem à neoplasia colorretal, o que determina a necessidade de

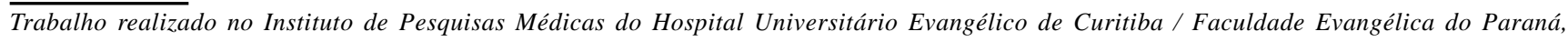
Curitiba, Paraná, Brasil.

$\overline{\text { Fonte de auxílio: }}$ Hospital Universitário Evangélico de Curitiba / Faculdade Evangélica do Paraná, Curitiba, Paraná, Brasil e Demanda Social CAPES. 
Rev bras Coloproct

Outubro/Dezembro, 2008
Expressão Citofotométrica do Marcador CD-34

no Adenocarcinoma de Cólon

João Batista Monteiro Tajra e Cols.
Vol. 28 vigilância destas lesões através de estudos genéticos de padrões de crescimento e degeneração da mucosa colorretal. O reconhecimento dos mecanismos de desenvolvimento das neoplasias transcorre por alteração entre a taxa proliferativa nas criptas e a de morte por apoptose, sendo necessária modificação genética em ambas para o crescimento tumoral. A inabilidade da célula para submeter-se a morte celular programada é um importante marcador da propensão a malignidade.

As alterações cromossômicas de cada tumor tornaram-se passos decisivos para o correto entendimento de seu aparecimento, sendo o acúmulo destas modificações genéticas o fator decisivo para o surgimento neoplásico. Várias alterações nos genes e seus produtos centrais afetam as fases do desenvolvimento celular, demonstrando o fenótipo molecular da célula tumoral ${ }^{2}$.

O prognóstico e o tratamento desta doença estão ligados ao momento do diagnóstico, invasão linfonodal, comprometimento local e disseminação à distância. O avanço na eficácia do tratamento nos últimos cinco anos se deve aos conhecimentos sobre a tumorigênese dos tumores de cólon e reto ${ }^{3}$.

A fase de crescimento e invasão tumoral tem na angiogênese seu principal suporte somado às características genéticas e fatores de crescimento diferentes das do processo normal de reparação ${ }^{4}$. Estes fatos tornam a densidade microvascular importante para avaliação prognóstica. Ela pode ser estudada com diversos marcadores, dentre eles uma glicoproteína denominada CD-34 ${ }^{5}$.

Pode-se utilizar para esta finalidade, o método padrão manual de coloração e leitura imunoistoquímica. Apesar de amplamente utilizado, a subjetividade, erros de coloração e dificuldade de comparação dos dados a partir deste método, suscitaram na literatura dúvidas metodológicas. O desenvolvimento de softwares de forma progressiva facilitou as análises comparativas dos diversos biomarcadores em relação às neoplasias. O sistema de múltiplos parâmetros de análise computadorizada de imagens, na atualidade, revelou em vários estudos ser mais rápido, confiável e menos passível de vieses, tornando as pesquisas de melhor confiabilidade $^{6}$.

Os objetivos deste estudo foram: 1. avaliar qual é a expressão citofotométrica computadorizada do marcador CD-34 no adenocarcinoma de cólon; 2. se ele apresenta alterações nas diferentes fases evolutivas na classificação modificada de Dukes; e
3. como se expressa quando localizado no cólon direito e esquerdo.

\section{MÉTODOS}

O estudo foi realizado no Instituto de Pesquisas Médicas (IPEM) do Programa de Pós-Graduação em Princípios da Cirurgia do Hospital Universitário Evangélico de Curitiba / Faculdade Evangélica do Paraná e no Laboratório de Citologia e Histopatologia Ltda, de Curitiba. Esta pesquisa foi aprovada pelo Comitê de Ética em Pesquisa da Sociedade Evangélica Beneficente de Curitiba.

O material de estudo foi constituído por amostras de peças de colectomias de 19 casos de adenocarcinomas de cólon fixadas em formol e conservadas em blocos de parafina. Este material foi proveniente do arquivo do Serviço de Patologia do Hospital das Forças Armadas de Brasília. Foram também registrados o grau da classificação de Dukes (B ou C) a que pertenciam, e o lado do cólon (direito ou esquerdo) onde se localizavam.

Os 19 blocos foram re-examinados após novos cortes, e coloração hematoxilina-eosina foi realizada por dois patologistas para confirmação do laudo e avaliação da viabilidade do material a ser submetido à imunoistoquímica (Figura 1). Terminada a confecção das lâminas foi realizada a análise quantitativa da imunoistoquímica, utilizando-se

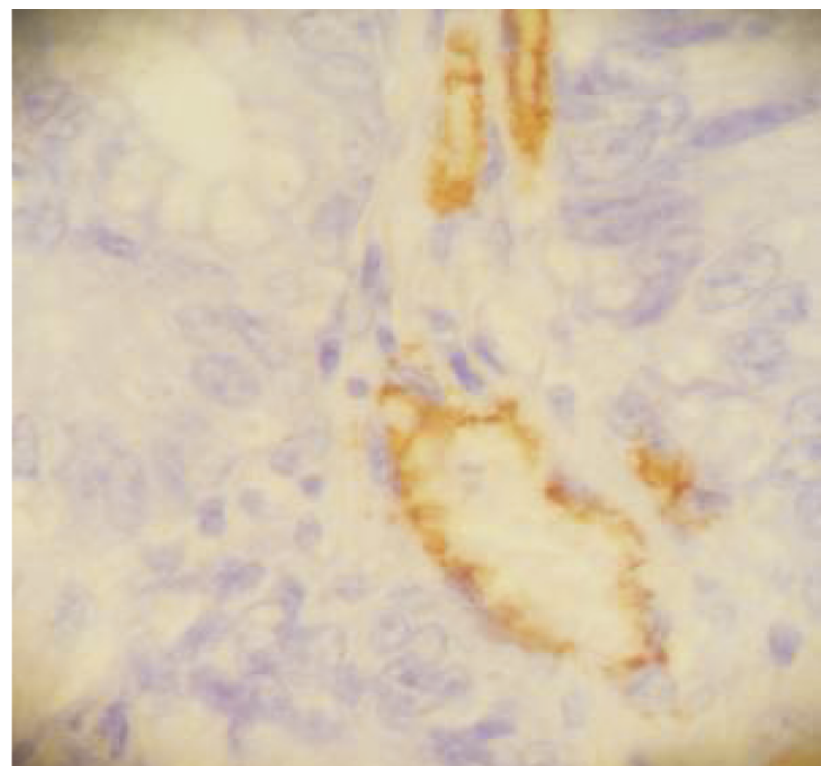

Figura 1 - Exemplo de marcação imunoistoquímica do CD-34. 
Rev bras Coloproct

Outubro/Dezembro, 2008
Expressão Citofotométrica do Marcador CD-34

no Adenocarcinoma de Cólon

João Batista Monteiro Tajra e Cols.
Vol. 28 o software IMMUNO®, sendo possível à leitura de 19 lâminas. Foram estudados o índice de marcação e a densidade óptica para determinar a expressão do marcador.

Os resultados obtidos foram descritos por médias, valores mínimos, valores máximos e desvios-padrão. A comparação entre grupos definidos pelo lado do cólon e pela classificação de Dukes foi feita usando-se o teste não-paramétrico de Mann-Whitney. A condição de normalidade dos dados foi verificada pelo teste de Kolmogorov-Smirnov. Valores de $P<0,05$ indicaram significância estatística.

\section{RESULTADOS}

Dos 19 adenocarcinomas, 13 eram moderadamente diferenciados, quatro bem diferenciados e dois mucinosos. Dez tumores eram localizados no cólon esquerdo, oito no direito e um no reto. O estudo da expressão cifotométrica do marcador CD-34 nos dois parâmetros, índice de marcação e densidade óptica, foi possível em todos. Na tabela 1 são apresentados os valores de média, mínimo, máximo e desvios-padrão obtidos.

Para o índice de marcação e a densidade óptica, testou-se a hipótese nula de que tumores com classificação tipo B de Dukes têm resultados iguais a tumores com classificação tipo $\mathrm{C}$, versus a hipótese alternativa de resultados diferentes. Na tabela 2 são apresentados os valores de média, mínimo, máximo e o desvio-padrão obtidos para tumores na classificação de Dukes.

Para o índice de marcação e a densidade óptica, testou-se a hipótese nula de que tumores de cólon direito têm resultados iguais a tumores de cólon esquerdo, versus a alternativa de resultados diferentes. $\mathrm{Na}$ tabela 3 são apresentados os valores de média, mínimo, máximo e desvio-padrão obtidos para tumores de cólon direito e esquerdo.

\section{DISCUSSÃO}

Durante a análise histopatológica realizada após a coleta do material, houve a necessidade de despre-

Tabela 1 - Valores estatísticos do índice de marcação e densidade óptica do marcador CD-34.

\begin{tabular}{llcccc}
\hline CD-34 & N & Média & Mínimo & Máximo & Desvio- \\
\hline Índice de marcação & 19 & 66,54 & 12,02 & 92,38 & 20,33 \\
Densidade óptica & 19 & 43,6 & 32,83 & 61,46 & 8,52 \\
\hline
\end{tabular}

Tabela 2 - Valores estatísticos dos tumores na classificação Dukes x CD-34.

\begin{tabular}{lcrccccc}
\hline Variável & Dukes & \multicolumn{1}{c}{ N } & Média & Mínimo & Máximo & Desvio Padrão & Valor de p \\
\hline Índice de marcação & $\mathrm{B}$ & 12 & 67,95 & 12,02 & 92,38 & 20,11 & 0,902 \\
& $\mathrm{C}$ & 7 & 64,12 & 28,05 & 87,15 & 22,10 & \\
Densidade óptica & $\mathrm{B}$ & 12 & 43,21 & 31,07 & 65,82 & 9,77 & 0,650 \\
& $\mathrm{C}$ & 7 & 44,27 & 35,87 & 54,00 & 6,30 & \\
\hline
\end{tabular}

Tabela 3 - Valores estatísticos do marcador CD-34 x lado do tumor.

\begin{tabular}{llrccccc}
\hline Variável & Lado do Tumor & $\mathbf{N}$ & Média & Mínimo & Máximo & Desvio Padrão & Valor de p \\
\hline \multirow{2}{*}{ Indice de marcação } & Direito & 8 & 58,93 & 28,05 & 77,96 & 16,82 & 0,033 \\
& Esquerdo & 11 & 72,08 & 12,02 & 92,38 & 21,58 & \\
Densidade óptica & Direito & 8 & 39,34 & 37,57 & 48,84 & 6,16 & 0,062 \\
& Esquerdo & 11 & 46,70 & 33,93 & 65,82 & 8,81 & \\
\hline
\end{tabular}


Rev bras Coloproct

Outubro/Dezembro, 2008
Expressão Citofotométrica do Marcador CD-34

no Adenocarcinoma de Cólon

João Batista Monteiro Tajra e Cols.
Vol. 28 zar alguns blocos por apresentarem defeitos como: tipo e tempo de fixação, ponto de fusão da parafina, desidratação defeituosa e quebra dos blocos por envelhecimento. Todo tecido que após a desparafinização, ou etapa anterior, era considerado de baixa qualidade foi excluído do estudo.

O trabalho com blocos armazenados para o uso em imunoistoquímica necessita de bom preparo na unidade de processamento, sendo este o ponto mais importante para evitar grandes perdas. Neste caso, o objetivo principal ao se trabalhar com este tipo de material, é preservar a arquitetura tecidual e a morfologia celular para adequada exposição dos antígenos a serem marcados. Os fixadores são os responsáveis diretos para a formação de um bloco de bom estado para estudo. Atualmente, são universalmente aceitas as soluções de formaldeído em concentrações variadas na forma tamponada.

Utilizou-se a técnica imunoistoquímica indireta da streptavidina-biotina. Este método é considerado cinco a 10 vezes mais sensível que o básico de imunoistoquímica da avidina-biotina ${ }^{7}$.

\section{Análise da imunoistoquímica}

Neste estudo utilizou-se sistema computadorizado de imagem que foi desenvolvido com o intuito de minimizar e tornar mais objetiva a análise dos fenômenos biológicos. Esta análise é feita através da quantificação e aumento das variáveis a serem estudadas, permitindo maior precisão no laudo final. $\mathrm{O}$ resultado assim obtido é dificilmente igualado através da interpretação somente humana da lâmina.

As pesquisas iniciais por este método foram desenvolvidas por KISS et al ${ }^{8}$. em 1989 com versão inicial representada pelo SAMBA 200 que através de up-grades está em constante evolução e no SAMBA 4000 foi a versão utilizada neste trabalho. O desenvolvimento deste equipamento permitiu a ampliação das pesquisas desta área, inclusive as quantificações histoquímicas de outros marcadores tumorais ${ }^{9}$.

O software escolhido para este trabalho foi o Imunno 4.00, versão 2.0 que utiliza apenas dois parâmetros, considerando os valores mínimos de mensuração citofotométrica para a análise: índice de marcação e densidade óptica. $\mathrm{O}$ fator decisivo para sua utilização foi a facilidade de manuseio que é realizado por inserção dos dados no sistema Windows da Microsoft $\AA$.

\section{Marcador tumoral}

Angiogênese é termo que se refere à formação de novos vasos a partir de um leito capilar existente. No começo da atividade de neovascularização, a neoplasia deve adquirir o chamado fenótipo angiogênico iniciado precocemente (início com 1 a 2 mm de tamanho tumoral) ${ }^{10,11}$.

O adenocarcinoma de cólon é um dos tumores de angiogênese mais estudados, depois do carcinoma de mama. O modelo baseia-se no índice de microdensidade vascular, que marca os vasos por técnicas de imunoistoquímica com Fator VIII, CD-31, CD34 e CD-105 ${ }^{12}$. A idéia nas pesquisas era determinar se os tumores com maior índice de vascularização tinham algum significado prognóstico com sobrevida, metástases e risco de recidiva ${ }^{13}$. Encontrar marcadores angiogênicos, significa caracterizar a precocidade do início neoplásico, projetar prognóstico e relacionar as diversas classificações oncológicas.

Neste estudo foi utilizada a molécula CD-34 que é uma glicoproteína transmembrana de cadeia única expressa em células progenitoras e células endoteliais de pequeno calibre, procurando-se esclarecer o seu potencial como marcador angiogênico.

Devido ao pequeno tamanho da amostra, os resultados encontrados neste estudo podem ser utilizados somente como sinalizadores para estudos futuros afim de que possam confirmar a hipótese.

\section{CONCLUSÕES}

1. O marcador CD-34 possui expressão discreta e constitui-se em fator de estudo importante na angiogênese colônica.

2. Em relação à classificação Dukes não houve diferença entre os tipos $\mathrm{B}$ e $\mathrm{C}$ no marcador CD-34.

3. Em relação ao lado do tumor há diferença significativa entre os de cólon direito em relação ao esquerdo no índice de marcação do CD-34 mostrando atividade angiogênica maior no lado direito do que do esquerdo. 
Rev bras Coloproct

Outubro/Dezembro, 2008
Expressão Citofotométrica do Marcador CD-34

no Adenocarcinoma de Cólon

João Batista Monteiro Tajra e Cols.
Vol. 28

ABSTRACT: Angiogenesis is considered to be one of the mechanisms responsible for the homeostatic balance among cells. During cell malignant degeneration, the unbalanced cell proliferation mechanisms demonstrate to be an important factor in cancer evolution and CD-34 is one important marker. Objective - To evaluate CD-34 biomarker expression through cytophotometric analysis of colon adenocarcinoma samples; to verify the presence of tumor marker expression in different stages of tumor samples according to Dukes modified classification; to determine eventual difference in CD-34 expression while tumor location is either in right or left colon. Methods - Nineteen samples were submitted to an immunohistochemical method, using anti-CD34 monoclonal antibody. Marked slides were analyzed by SAMBA system using Immuno 4 software. Biomarker expression consisted in label index and optical density. The parameters considered under investigation were tumor expression, its intensity, correlations to Dukes' classification and tumor's side. Results - The mean rate of CD-34 expression was 66.54, and optical density 43.60. Regarding Dukes' classification, 12 samples B-type presented label index 67.95 and optical density 43.21; seven Ctype, label index was 64.12 and optical density 44.27. It was not possible to identify any difference related to Dukes' classification. Tumor side reflected significant difference in label index, but not in optical density. Eleven samples on the left presented 72.08 of label index and 46.70 of optical density. Eight right, demonstrated label index of 58.93 and optical density of 39.44. Conclusions - CD-34 marker presented a low expression as an angiogenesis marker in colon tumors with no difference between Duke's tumors type-B and type-C. The tumor had higher angiogenic activity in the right than in left colon.

Key Words: Colon cancer. Angiogenesis. CD-34. Immunohistochemistry.

\section{REFERÊNCIAS}

1. Jemal A, Murray T, Ward E, Samuels A, Tiwari RC, Ghafoor A, et al. Cancer statistics, 2005. CA Cancer J Clin. 2005 JanFeb;55(1):10-30.

2. Hanahan D, Folkman J. Patterns and emerging mechanisms of the angiogenic switch during tumorigenesis. Cell. 1996 Aug 9;86(3):353-64.

3. Fox SB, Gasparini G, Harris AL. Angiogenesis: pathological, prognostic, and growth-factor pathways and their link to trial design and anticancer drugs. Lancet Oncol. 2001 May;2(5):27889.

4. Huerta S, Goulet EJ, Livingston EH. Colon cancer and apoptosis. Am J Surg. 2006 Apr;191(4):517-26.

5. Krause DS, Fackler MJ, Civin CI, May WS. CD-34: structure, biology, and clinical utility. lood. 1996 Jan 1;87(1):1-13.

6. Goddard JC, Sutton CD, Furness PN, Kockelbergh RC, O'Byrne KJ. A computer image analysis system for microvessel density measurement in solid tumours. Angiogenesis. 2002;5(12):15-20.

7. Giorno R. A comparison of two immunoperoxidase staining methods based on the avidin-biotin interaction. Diagn Immunol. 1984;2(3):161-6.

8. Kiss R, de Launoit Y, Danguy A, Paridaens R, Pasteels JL. Influence of pituitary grafts or prolactin administrations on the hormone sensitivity of ovarian hormone-independent mouse mammary MXT tumors. Cancer Res. 1989 Jun 1;49(11):2945-51..

9. Gasparin Jr P, Budel V, Petein M, Pasteels J, Kiss R. DNA histogram typing and DNA index measurements in 508 invasive breast carcinomas from fine-needle aspirates and imprint smears as opposed to formalin-fixed paraffin-embedded tissues. Int. J. Oncology. 1994;5:589 -95.

10. Folkman J. Seminars in Medicine of the Beth Israel Hospital, Boston. Clinical applications of research on angiogenesis. N Engl J Med. 1995 Dec 28;333(26):1757-63.

11. Hanahan D, Weinberg RA. The hallmarks of cancer. Cell. 2000 Jan 7;100(1):57-70.

12. Weidner N, Semple JP, Welch WR, Folkman J. Tumor angiogenesis and metastasis-correlation in invasive breast carcinoma. N Engl J Med. 1991 Jan 3;324(1):1-8.

13. Saclarides TJ. Novidades e controvérsias no tratamento das doenças Clínicas Cirúrgicas da América do Norte.Webmedicos $1997 ; 1$.

Endereço para correspondência:

JOÃO BATISTA MONTEIRO TAJRA

Al. Augusto Stellfeld, 1980

CEP 80730-150

Bigorrilho - Curitiba - PR - Brasil.

Tel: (41) 32405488

E-mail: ipem@evangelico.org.br 